\title{
Investigation of College Students' Entrepreneurial Simulation Comprehensive - Experiment Construction under Constructivism
}

\author{
JIA Fengling \\ Lecturer, Experimental Teaching Ministry \\ Gui Zhou University of Finance and Economics \\ China, Guiyang \\ Email:304705458@qq.com
}

\author{
(SUBMITTED BUT NOT PRESENTED)
}

\author{
$\mathrm{HE} \mathrm{Xu}$ \\ Professor, Experimental Teaching Director \\ Gui Zhou University of Finance and Economics \\ China, Guiyang
}

\begin{abstract}
Starting from the teaching point of establishing college students' entrepreneurial simulation comprehensive experiment, based on the theoretical basis of constructivism, this paper comprehensively analyzed the motivations and objectives of establishing college students' entrepreneurial simulation comprehensive experiment and proposed new ideas and new methods of entrepreneurial simulation comprehensive experiment. With comprehensive and labor division organization, it made overall design and established college students' entrepreneurial simulation comprehensive experiment combining integrity and opposability. Then, it deeply studied the teaching methods in order to provide references for reforming and enhancing the entrepreneurial experimental teaching mode of college and universities.
\end{abstract}

Keywords-Constructivism; Entrepreneurial simulation; Entrepreneurial; Experimental teaching mode

\section{INTRODUCTION}

College students' entrepreneurial simulation comprehensive experiment is an important part of experimental teaching. The success of this course has direct impact on the cultivation of college students' ability of innovation and entrepreneurship. Faced with the requirements of current severe employment pressures and sustainable economic development, the state has issued a series of policies and measures to encourage universities to focus on training students' capacity of innovation and entrepreneurship. The 18th party congress report also clearly stated: "Promote entrepreneurship employment, perfect youth employment focusing on college graduates and enhance workers' abilities of employability and entrepreneurship." As the main positions to carry out entrepreneurship education of college students, colleges and universities have introduced corresponding policies and measures of entrepreneurship education, such as creating lectures about innovation and entrepreneurship, organizing college students' entrepreneurship competitions and others. However, there are still some problems: lacking systematic teaching contents of innovation and entrepreneurship, vague educational philosophy and educational model, especially lacking experimental teaching

Project source: GuiZhou Province experimental teaching demonstration center for innovation and entrepreneurship(2012-2015). model of training students' abilities of innovation and entrepreneurship in the teaching of entrepreneurial simulation experiment. Therefore, building and implementing relative teaching models of college students' entrepreneurial simulation experiment to effectively cultivate students' abilities of innovation and entrepreneurship according to the present situation of college students' entrepreneurial simulation experiment teaching have become urgent tasks of colleges and universities in the teaching of entrepreneurial simulation experiment.

\section{RESEARCH STATUS OF BUILDING EXPERIMENT TEACHING UNDER CONSTRUCTIVISM}

Proposed by the Swiss psychologist Jean Piaget in 1996, constructivism teaching concept was the critique and development of the traditional teaching concept[1]. The teaching ideas of constructivis m were mainly summarized into six aspects of "knowledge view", "learning view", "student view", "ro les and functions between teachers and students" and "learning environment and teaching principles" [2]. Leigh Ann Haefner and Carla Zembal-Sau from University of California divided the research and development of university college students' entrepreneurship experimental teaching into three stages of independence, interaction and cooperation [3]. Wherein, the research target of the experimental teaching of the independence stage (from late 18 century to middle 19 century) was to train scientific personnel, paying more attentions to the structure of human behaviors and ignoring the mental process of the behaviors[4]; the experimental teaching research of interaction stage (since the 1850s) had blended views of information processing, mental development and problem solving and combined with the latest psychology education theory, providing more effective methods and means for guiding experimental teaching; the research of the cooperation stage mainly took constructivism as guidance, emphasizing the creation of experimental situations to promote the students' knowledge development and particular emphasizing on promoting the development of students' self-control and reasoning ability in the experiment[5]. Stevenson et al. presented that the study of entrepreneurship opportunity under application of constructivism means that an opportunity idea 
may make the entrepreneurs perceive a desirable and feasible imagined future[6]. Weick thought that the key of the meaning construction lays in language, exchange and communication, which can be constructed through this ways, scenarios, organizations even the external environment of language and communications [7].

According to the situation of domestic and overseas research of the experimental teaching of college students' entrepreneurship under constructivism, the research relatively develops slowly and most studies focus on the planning level of the experimental teaching; there are fewer researches about teaching of entrepreneurship simulation experiment. In 2001, Zhang Lin proposed three levels of implementing teaching of entrepreneurship experiment in of "basic experiment, comprehensive experiment and simulation research" and divided the experimental stages of the four years in university. He thought that the first year is the basic experiment training stage, the second year is the professional basis or professional technology basis experimental stage, the third year is the training stage of comprehensive experimental ability of implementing entrepreneurship simulation, the fourth year is the simulation stage of thematic design. Zhang Weisen and others organized entrepreneurship experimental teaching according to the four levels of "preliminary type, basic type, comprehensive design type and topic type". In 2010, Li Yongjiu proposed to strengthen the students' independent thinking ability, innovative ability and entrepreneurship. Constructivism teaching provides possibility for the transition of the experimental teaching mode. In 2013, Shen Junxia raised the entrepreneurship education thinking system based on constructivism, which was expanded from the four dimensions of scenarios creation, team learning, service practices and construction of new teacher-student relationships. In 2014, Feng Liqin et al. described the applications of constructivism in the design of virtual experiment teaching.

Overall, the research of the teaching of entrepreneurship experiment under constructivism has been deepening. Constructivism believes that the knowledge of education generates from the interaction process between human mind and the external objects. Speaking on this level, the teaching of college students' entrepreneurial simu lation comprehensive experiment needs experimenters to interact with the external experimental objects. Therefore, as the theoretical basis of the design of university experimental teaching, the constructivis $m$ is more conducive to explore the natures of the teaching of college students' entrepreneurial simulation experiment. Meanwhile, with the continuously increased requirements of society for capacities of top talents, the requirements of further developing students' entrepreneurial and innovation capacities through designing college students' entrepreneurial simulation comprehensive experiment are increasingly prominent. As a result, it is a subject studied by many investigators at current to cultivate students' entrepreneurial practice abilities by building college students' entrepreneurial simulation comprehensive experiment and grasping the overall targets of the entrepreneurial experimental teaching.

\section{RESEARCH PROCESS OF COLLEGE STUDENTS' ENTREPRENEURIAL SIMULATION COMPREHENSIVE EXPERIMENT UNDER CONSTRUCTIVISM}

\section{A. Causes analysis of the teaching design}

Teaching of entrepreneurial simulation experiment is an important way to validate what the students have learned and to cultivate the students' innovative spirit and entrepreneurial abilities. In recent years, with the advancement of experimental teaching reform, most financial colleges have made teaching reform to improve the cultivation of students' entrepreneurial abilities. Some financial colleges also proposed training program for talents with "innovative and entrepreneurial sprits" or having "potentials for sustainable development" and implemented relevant entrepreneurial experimental teaching. Besides, some traditional entrepreneurial experimental teaching simulation soft wares of finance, marketing, logistics and others are increasingly adopted by colleges and universities. Many colleges and universities are working harder in students' entrepreneurial simu lation experiment teaching. In order to further investigate the implementation effects of the simulation experimental teaching and to understand the teaching effects of entrepreneurial simulation experiment of local finance and economics colleges and universities, this paper conducted questionnaire survey about the cultivation satisfaction of innovation and entrepreneurship experimental teaching of local finance and economics colleges and universities. the specific circumstances as shown in Figure.1.:

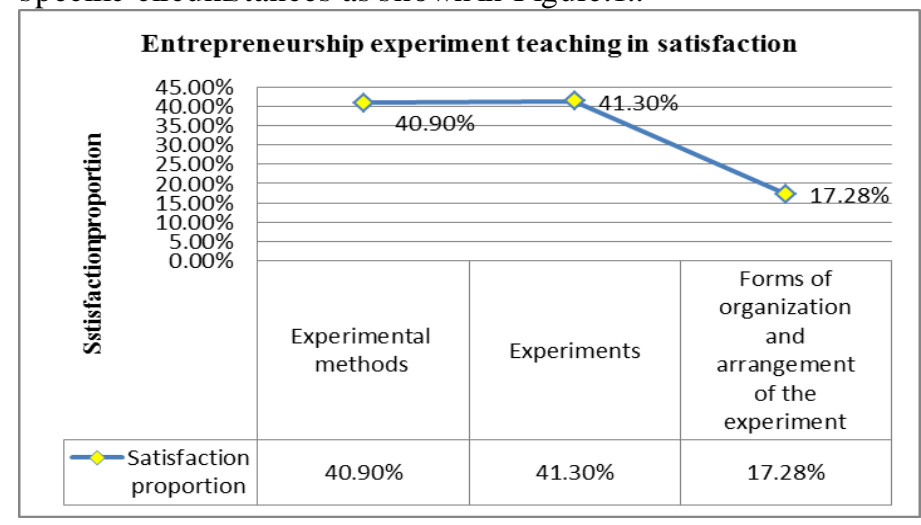

Fig. 1. Implementation of experimental teaching sat isfaction

There is a big gap between the implementation and objectives of entrepreneurship experimental teaching of local finance and economics colleges and universities, in terms of experimental ways, contents, organizations and arrangements. At the same time, according to relevant open questionnaire surveys, the students' feedbacks of the implementation effect are not optimistic. Form the overall feedback results of the entrepreneurial experimental teaching, it can be seen that there are still some problems. The main problem is that the traditional experiment teaching software lacks of practical business background and lacks of systematic, open, interactive and flexible, dynamic characteristics because the design is too simple and the designed business process is too fixed. They tend to focus on training some single point of knowledge, 
without clear inherent logic link between the knowledge points and lack of communication between the business contacts, so that the experimental classes become simple applications of experiment software, which cannot make students have real experience. As a result, the students' enthusiasmis nothigh and the teaching effect is not ideal.

Students hope to contact with real companies to experience and apply their professional knowledge. Neither the conventional entrepreneurial experimental teaching process of universities nor the corporate entities are temporarily unable to provide such internships to complete the teaching tasks. Therefore, it is necessary to build a more complete business environment according to a variety of teaching methods under constructivism so that the students can do role simulation exercises in the entire process from creating business to operating the business and managing the manufacturing with the professional knowledge they have mastered. Thus, it is imperative to conduct the entrepreneurial simulation comprehensive experiment which can visually display real business, simulating the interaction, cooperation and competition between real supply chains in the laboratories of colleges and universities.

\section{B. New ideas of teaching design of college students' entrepreneurial simulation under constructivism}

Based on the theoretical system of constructivism, highlighting the training of students' comprehensive abilities and deepening the philosophy of entrepreneurial simulation teaching reform, college students' entrepreneurial simulation comprehensive experiment determined the new ideas of teaching reform of "taking professional collaborative experiments as basis, the business operations simulation confrontation as content and improving students' entrepreneurial ability as objective to deepening the reform of talent training mode" under constructivism. The reform pattern is shown in Figure.2. and the research ideas of the teaching designing cludes the following areas

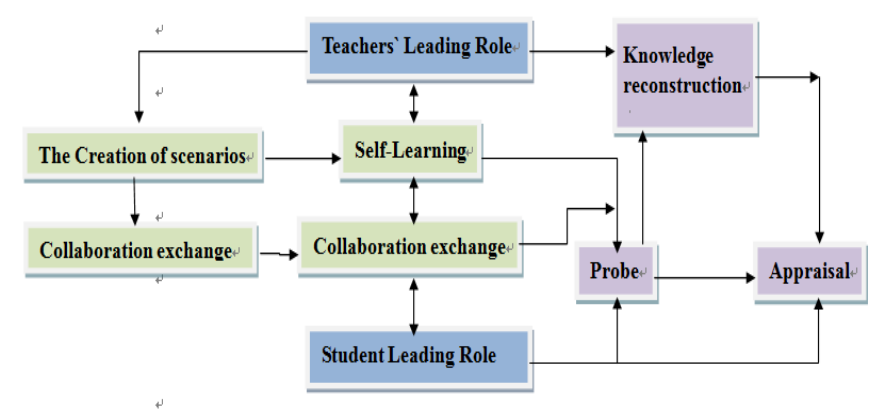

Figure.2. Integrated business simulation experiments autonomous teaching mode

1) Change teaching concept, explore and construct new experimental teaching mode of "students' autonomous learning supplemented by teachers". Student becomes the main body of teaching and learning becomes the center of teaching activities. The roles of teachers change from teaching to designing, organizing, guiding, monitoring and evaluating.
2) Achieve mutual combination of different majors and cultivate students' teamwork sprit. The contents of entrepreneurial simulation comprehensive experiment break the curriculum, professional and disciplinary boundaries, integrating design relevant knowledge. Students from $\mathrm{m}$ ifferent disciplines work together to complete the course contents, making them understand the teamwork spirit, recognize the power of teamwork, which greatly helps to foster and improve their comprehensive quality.

3) Implement multidimensional learning evaluation system and abandon traditional test evaluation mode. The experimental teaching evaluation can realize the combination of students' self-evaluation and teachers' evaluation, selfevaluation and team evaluation, qualitative evaluation and quantitative evaluation, achieving multi-dimensional evaluation methods of experimental teaching.

4) Carry out teaching activities using network information technology. Students can use the entrepreneurial business information system network platform to independently collect and analyze information of study status, independently customize learning system and independent participate in business decision-making analysis to complete related experiments of the experimental evaluation.

\section{New teaching methods of college students'entrepreneurial simulation teaching under constructivism}

Highlighting the student-centered and teacher-directed teaching ideas and based on constructivism, entrepreneurial simulation comprehensive experiment fully played the students' initiatives and constructed a series of independent experimental teaching methods with distinctive characteristics.

\section{1) Teaching method of "learning by doing"}

The "learning by doing" model establishes a teaching mechanis m co mb ing "teaching", "doing" and "learn ing" with the essence of learning in the process of "doing" and achieving the purpose of study by "doing". In the teaching process of entrepreneurial simulation comprehensive experiment, teachers teach the key points first and then the students engage in actual "doing". The good results of learning innovation and entrepreneurship can be achieved by getting feedbacks of the innovation and entrepreneurship mentor and peer reviews. In the operation of the entrepreneurial simulation process, every entrepreneur team has an entrepreneurship mentor to solve the variety of concrete and comprehensive complex problems faced by the students in the entrepreneurial process. The students will independently inquire, discover, understand and learn relevant knowledge to solve the problems in the entrepreneurial process, according to real requirements.

\section{2) Project teaching method}

In project experimental teaching method, teachers and students jointly implement the whole design project of innovation and entrepreneurship. In the process of completing the project, the students actively discover problems and explore the problems, repeatedly do experiments by trial and error and ultimately exercise and improve related abilities of innovation and entrepreneurship. The teaching innovation and entrepreneurship projects mainly come from the actual needs 
of the enterprises cooperating with the universities as well as the research innovation and entrepreneurship of the mentors. It is in line with social reality and has good guidance effect to combine the flexible project with the relatively fixed experimental teaching.

\section{3) “Salon" teaching method}

Carrying out innovation and entrepreneurship salon by simulate comprehensive experiment to discuss creative or entrepreneurial projects in groups, write and analyze the discussion report, make the individual students to summarize and share with other teams, so that students can realize, understand, re-understand, rediscover and re-create under the guidance of a number of instructors. This teaching method combines salon discussion and experimental teaching, having the advantages of both. It has outstanding results in terms of training and inspiring students' learning enthusiasm, innovation awareness and entrepreneurship anilities.

\section{CONSTRUCTION OF COLLEGE STUDENTS' ENTREPRENEURIAL SIMULATION COMPREHENSIVE EXPERIMENT}

\section{A. Construction of college students'entrepreneurial simulation comprehensive experiment}

Based on the core teaching design ideas of studentcentered, teachers-helped serving as mentors under constructivism, college students' entrepreneurial simulation comprehensive experiment fully plays the students' initiatives in organization and process design. The implementation is divided into five stages of mobilization training, organizing teams, planning contest, real situation simulation and summarizing. The specific implementation process is shown in Figure .3.:

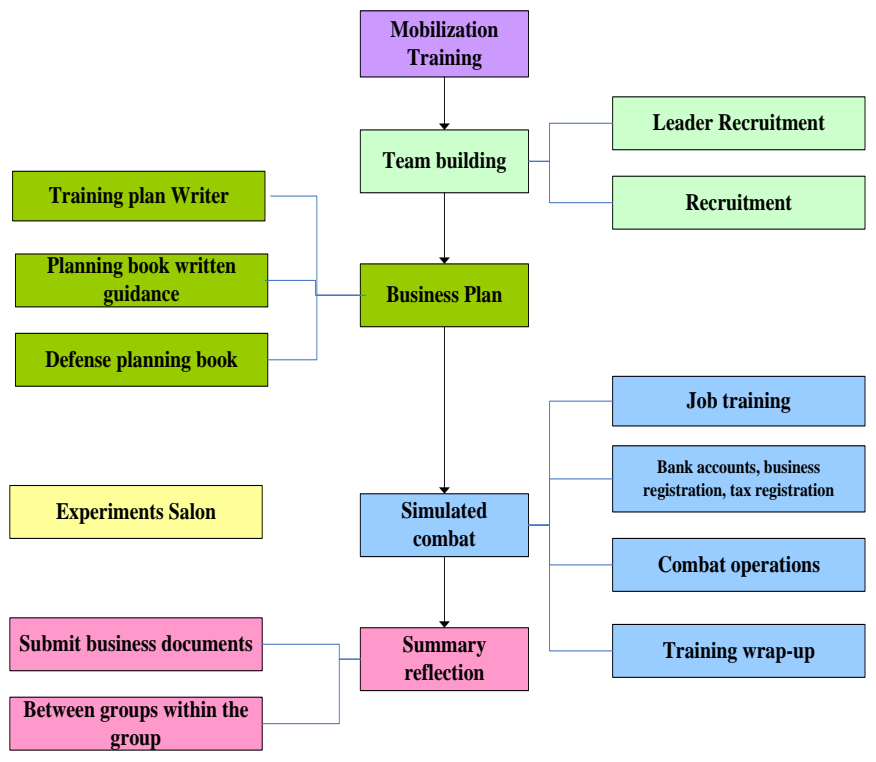

Figure3. The comprehensive business simulation experiments implemented total flow

By organizing teams, business plan competitions, business simulation, summarizing and other interrelated aspects, the designing process of entrepreneurial simulation comprehensive experiment can make students have a better understanding of the actually creation and operation processes of enterprises, have a clear understanding of the positioning features of their majors from a high level, so as to improve their practical working abilities and broaden their vision of the future.

- Mobilization training. This stage mainly include introducing courses, scheduling stages, team organizing rules and scoring rules, performance evaluation details and other related arrangements of the teaching implementation of the entrepreneurial simulation comprehensive experiment.;

- Organizing teams. A number of students majoring in human resource management form several human resource enterprises to draw up recruitment plans to recruit students of economy and management majors and organize teams under the authority of the board (played by the instructors) and according to the roles requirement of the simulation environment.

- Planning contest. Each team finishes the corresponding plans according to their roles in the simulated market. Writing business plans for well-known enterprises in Guizhou Province to make students understand the actual situation of the enterprise and reply in support of their ideas by simulating financing scenarios. There will be team activities in the planning contest in order to make the students understand the importance of teamwork and communication and better combine the theoretical knowledge and practical activities. Teams passing this stage will go to the subsequent stage of real situation simulation and those not passing this stage need to modify the plans and defend again.

- Real situation simulation. The instructors arrange the teams passing the third stage to take part in the simulated combat, playing the corresponding market roles (such as suppliers, manufacturers, government agencies, banks, etc.). Six quarters of simulated operation activities should be completed within 2-3 weeks.

- Summarizing. After the real situation simulation, the student teams should sort the original documents, write experiment summary reports and prepare reporting materials according to the operations of their team roles and combining their own learning. Then, they will conduct assessment scoring to the members of other teams in the experiment information system.

B. Design and construction of simulated market environment of college students' entrepreneurship

The entrepreneurial simulation comprehensive experiment will be carried out by the process combining integrity and opposability, taking manufacturing business as the core of the simulation. By organically combining the external business environment with the simulation management of service-oriented enterprises, various parts have normal business contact with each other (such as buying and selling negotiations between suppliers and manufacturers, the deposit, loan and transfer operations between banks and 
enterprises), which forms a highly simulated social market environment.

Closely connect relevant points of different majors according to the social demands of talents. The design the of role implementation contents mainly fusses on the professional courses, migrating the professional knowledge to specific actual operations. The contents of college students' entrepreneurial simu lation not only involve a large number of applications of professional theoretical knowledge, but also involve a large number of practical business common knowledge (such as industrial and commercial code, tax registration, contract writing and signing, preparing loan materials, etc.) which are better supplement of the contents not involved in the professional theory courses. Meanwhile, in the scenario design of the college students' entrepreneurial simulation experiment, it is better to provide as much opportunities as possible to make the students apply what they have learned into real applications, truly achieving "learning from doing and doing in learning". The designed market environment include 10 roles of human resources business, government service agencies, suppliers, manufacturers, banks, insurance companies, accounting firms, e-commerce businesses, IT organizations and management consulting firms. the model type figure 4 as follows:
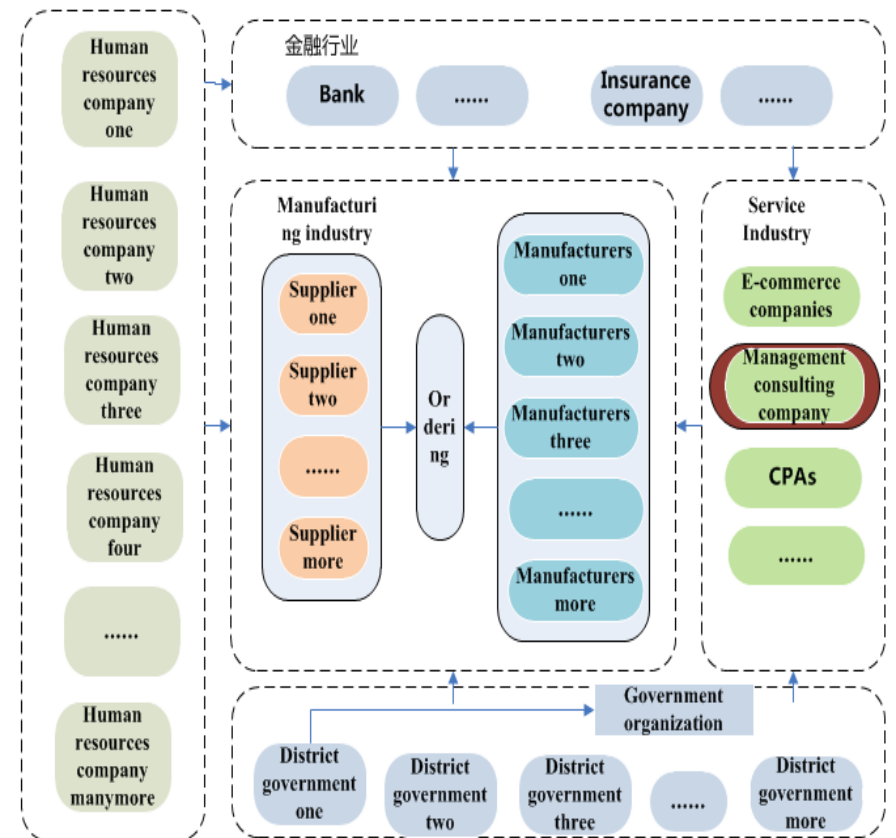

Figure.4. Business simulation market type map

The entrepreneurial simulation comprehensive experiment takes enterprise (suppliers and manufacturers) as the main role and other roles as service agencies. In order to better simulate the actual market and generate a dynamic mechanis $m$ of competition, the manufacturers and suppliers are effectively connected by the way of holding purchasing meetings, which changes the past situation that the parametric variables of the procurement were set by the system. The contents of the supplier simulation make numerous modifications and improvements of the contents of original sand table simulation, connecting downstream manufacturing enterprises and setting the beginning balance of the enterprises' reporting. At the same time, it will not provide the students with balance sheets and income statements, but provide them with a summary account balance report, letting them fill out the balance sheet and preparing journalizing according to requirements.

The experimental contents design of the manufacturers changes the original top-boss simulation operation mode, so that the settings of the operating environment are more in line with the actual situation of China's economy. The introductions of handmade balance sheet, income statement and cash flow statement ask students to take the reports they have made as basis for decision making, which not only is more in line with the actual situation of business operation, but also facilitates the training of students' relevant professional working abilities.

\section{CONCLUSIONS}

By the construction and implementation of college students' entrepreneurial simulation comprehensive experimental program under constructivism, this paper, on one hand, achieved the organic connection of various business environments, not only changing the original frag mented state of experiment contents, but also having competitiveness and opposability, which can fully stimulate students' interest and connects their interest and entrepreneurial practices together. On the other hand, it explored and constructed a new entrepreneurial simulation experimental teaching mode. The college students' entrepreneurial simulation comprehensive experimental program is completely different from the traditional experiment courses in content design, organization and implementation ways. The content design of all aspects focuses on rulemaking and reserves spaces for students to play their initiative and creativity. In the teaching process, teachers serve as supervisors and collaborators.

\section{REFERENCES}

[1] LinCangqiong. Constructivism use in anatomy education reform theory of [J]. Anatomy,2003,26(6):622-623.

[2] LIJiamen, Long Dahong, Hong Lepeng. Apply Constructivist Teaching Theory and reflection $[\mathrm{J}]$ in the local anatomy teaching. China Practical Medicine, , 2008, 3(28): 210-212.

[3] http://www.edu.cn/20050114/3126789.shtml.

[4] Googland J I . Planning and Organizing forTeaching[M] . Nation Education Association, 1963: 29.

[5] Herrlee G Greel. The Origins of State craft inChina[M]. Chicago: University of ChicagoPress, 1970.

[6] Stevenson $\mathrm{H}$ and Jarillo J.A paradigm of entrepreneurship:Entrepreneurial management[J].Strat egic Entrepreneurship Journal,1990,11(4):14-26.

[7] WEICK $\mathrm{K} \quad \mathrm{E}$.Sensemaking in organization [m].Thousang Oaks,CA.Sage, 1995.

[8] Hu Jian. Application Personnel Training Model Innovation in Financial Institutions place [J]. Chinese higher education, 2009,(21).

[9] Biggs J . Testing: To Educate or to Select ? [M] . Hong Kong Educational Publishing Co, 1996: 29.

[10] Qi Yongqin. Innovation and Higher Education Reform Experiment [J] Research and Exploration in Laboratory, 2002，21(3) : 9. 
[11] Wang Zhijun. Also on the Open Experimental Teaching [J] Research and Exploration in Laboratory, 2010, 29 (3) : 99.

[12] Morris. Ideas from Science: An Experiment in Adult Education [J].physics Education,2003(1):35-38.

[13] Leigh Ann Haefner, Carla Zeubal-Saul . Learning by Doing? Prospective Elementary Teachers'Developing Understandings of Scientific Inquiry and Science Teaching and Learning[J]. International Journal of Science Education, 2004， 26(13) : 1653-1674.

[14] ZhangLin. To investigate the experimental curriculum system reform [J]. Research and Exploration in Laboratory, 2001(4) : 15-16.

[15] ZhangWei sen, YueJunfeng. Reform and implementation of university physics experiment course system and teaching mode [J]. University physics experiments, 2001(3) : 18 .
[16] XuPing. Accounting staff capacity framework [D]. Xiamen: Xiamen University,2006.

[17] Zheng Chun sheng, Our ability to evaluate the differences bet ween urban and rural students' self - Based on 175 colleges and universities nationwide survey $[\mathrm{J}]$ social scientists, 2012,(4): 110-113.

[18] Wang Baoxing, Experimental research universities teaching design based on constructivism [D]. Beijing University of Technology, 2012.05.

[19] LI Mang. Constructivism in the end gave us what [J]. China Educational Technology, 2002(6)11. 